\title{
Warfarin control in Hong Kong clinical practice: a single-centre observational study
}

\author{
Amy SM Lam, Isis MH Lee, Simon KS Mak, Bryan PY Yan, Vivian WY Lee *
}

\section{A B S T R A C T}

Introduction: Time in therapeutic range (TTR) assesses the safety and effectiveness of warfarin therapy using the international normalised ratio. This study investigated the TTR in Hong Kong patients using both European and Japanese therapeutic ranges and patients' economic and clinical outcomes. Predictors of poor warfarin control and patient knowledge concerning warfarin therapy were assessed.

Methods: A 5-month observational study with retrospective and prospective components was conducted in the Prince of Wales Hospital. The study examined electronic patient records of patients who received warfarin for at least 1 year during the period from January 2010 to August 2015. Patient knowledge was assessed via phone interview using the Oral Anticoagulation Knowledge (OAK) test.

Results: In total, 259 patients were included; 174 completed the OAK test. The calculated mean TTR was $40.2 \pm 17.1 \%$ (European therapeutic range), compared with $49.1 \pm 16.1 \%$ (Japanese therapeutic range) $[\mathrm{P}<0.001]$. Mean TTR was higher in patients with atrial fibrillation than in patients with prosthetic heart valve $(\mathrm{P}<0.001)$. The abilities of TTR to predict clinical and economic outcomes were comparable between European and Japanese therapeutic complications and lower healthcare costs. Patients with younger age exhibited worse TTR, as did those with concurrent use of furosemide, famotidine, or simvastatin. Mean OAK test score was $54.1 \%$. Only $24(13.8 \%)$ patients achieved a satisfactory overall score of $\geq 75 \%$ in the test.

Conclusion: Warfarin use in Hong Kong patients was poorly controlled, regardless of indication. Patient knowledge concerning warfarin use was suboptimal; thus, additional patient education is warranted regarding warfarin.

\section{Hong Kong Med J 2020;26:294-303 \\ https://doi.org/10.12809/hkmj208416

\author{
${ }^{1}$ ASM Lam, BPharm, MSc \\ ${ }^{1}$ IMH Lee, BPharm \\ BPY Yan, MB, BS, FRACP \\ ${ }^{3}$ VWY Lee *, PharmD, BCPS (AQ Cardiology)
} \\ ${ }^{1}$ SKS Mak, BPharm}

\section{School of Pharmacy, Faculty of Medicine, The Chinese University of Hong Kong, Hong Kong \\ Department of Medicine \& Therapeutics, Faculty of Medicine, The Chinese University of Hong Kong, Hong Kong \\ Centre for Learning Enhancement and Research, The Chinese \\ University of Hong Kong, Hong Kong}

* Corresponding author: vivianlee@cuhk.edu.hk

New knowledge added by this study

- Warfarin control, in terms of time in therapeutic range (TTR), was suboptimal (40.2\% with European therapeutic range and $49.1 \%$ with Japanese therapeutic range), regardless of indication.

- Abilities of TTR to predict clinical and economic outcomes were comparable between European and Japanese therapeutic ranges.

- Patients with younger age exhibited worse TTR, as did those with concurrent use of furosemide, famotidine, or simvastatin.

- Only $13.8 \%$ of interviewed patients achieved a satisfactory overall score on the Oral Anticoagulation Knowledge test.

Implications for clinical practice or policy

- Warfarin is the most commonly prescribed anticoagulant in Hong Kong. However, warfarin control was suboptimal; this poor control was associated with worse clinical and economic outcomes. Poor anticoagulation control could increase healthcare expenses.

- Abilities to predict outcomes were similar between European and Japanese therapeutic ranges. Associations of suboptimal warfarin control with unfavourable outcomes were robust for both therapeutic ranges.

- Despite the establishment of a warfarin clinic and availability of educational materials and discussions regarding warfarin use, patient knowledge concerning warfarin therapy remains unsatisfactory, compared with prior studies in Hong Kong. Additional patient education concerning warfarin use is warranted. New approaches may be useful to deliver medication knowledge. 


\section{Introduction}

Warfarin, an oral vitamin $\mathrm{K}$ antagonist, has been widely used as anticoagulant therapy for the treatment and prophylaxis of thromboembolic disease. Patients with atrial fibrillation (AF) exhibit elevated risks of mortality and morbidity, including fivefold greater risk of stroke and threefold greater risk of heart failure, compared with individuals without AF. ${ }^{1,2}$ In patients with prosthetic heart valve (PHV), the incidence of PHV thrombosis was $0.5 \%$ to $6 \%$ per patient-year, depending on the prosthesis site. ${ }^{3}$ Warfarin has been shown to significantly reduce the risk of stroke in patients with non-valvular AF and the risk of embolism in patients with PHV. ${ }^{4,5}$

To ensure the efficacy and safety of warfarin therapy, strict control of the international normalised ratio (INR) is required. One measurement of INR does not indicate whether warfarin dose is appropriate for a given patient. Instead, time in therapeutic range (TTR) is commonly used in clinical practice. According to the European Society of Cardiology Guidelines for the management of AF, the ideal TTR is regarded as $70 \% .{ }^{6}$ However, warfarin control in clinical practice is reportedly unsatisfactory worldwide. ${ }^{7,8}$ Poor TTR has been associated with elevated risks of major haemorrhage, ischaemic stroke, and all-cause mortality. ${ }^{9}$

Hong Kong is currently following the European Society of Cardiology Guidelines for the Management of Atrial Fibrillation with respect to warfarin; these guidelines recommend INR control between 2.0 and 3.0 in patients with normal heart valve and between 2.5 and 3.5 in patients with PHV. ${ }^{6}$ In contrast, the Japanese Guidelines for Pharmacotherapy of Atrial Fibrillation (JCS 2013) recommend INR control between 2.0 and 3.0 in patients aged $<70$ years or patients with PHV, and between 1.6 and 2.6 in patients aged $\geq 70$ years. ${ }^{10}$ This recommendation is based on the findings of a study in which the incidence rate of major haemorrhagic complications was determined to be lower at INR between 1.6 and 2.6. ${ }^{11}$ It remains unknown whether additional benefits would be obtained by application of Japanese guidelines in Hong Kong.

There are extensive drug-drug interactions, drug-herb interactions, and drug-food interactions of warfarin, which may affect anticoagulation control. $^{12,13}$ To assure the efficacy and safety of warfarin, patient education concerning warfarin is needed. ${ }^{14,15}$ However, a study in 2008 showed that only one in six patients with AF underwent regular INR examinations in China; patients with AF also commonly exhibited minimal knowledge concerning the importance of regular INR examinations. ${ }^{16}$

The study aimed to investigate the adequacy of warfarin control in clinical practice in Hong Kong by means of the TTR; it compared warfarin outcome prediction using European and Japanese

\section{華法林控制的臨床實踐：香港單中心觀察性研究}

$$
\text { 林淑敏、李文萱、麥嘉成、甄秉言、李詠恩 }
$$

引言：患者在治療期間達到目標INR的時間百份比（TTR）一般用作 評估華法林治療的安全和有效性。本研究使用歐洲和日本標準以及患 者的經濟和臨床結果檢視香港患者的TTR, 並評估華法林控制不佳的 預測因子以及有關患者對華法林治療的認識。

方法: 在威爾斯親王醫院進行為期五個月的回顧及前瞻性觀察研究, 檢視 2010 年 1 月至 2015 年 8 月期間接受華法林治療至少 1 年的患者的電 子患者記錄。使用口服抗凝知識（OAK）測試以電話訪談評估患者對 華法林治療的認識。

結果：共259例被納入研究, 174 例完成OAK測試。以歐洲標準計算的 平均TTR為 $40.2 \pm 17.1 \%$, 以日本標準計算的平均TTR為 $49.1 \pm 16.1 \%$ $(\mathrm{P}<0.001)$ 。心房纖顫患者的平均 TTR 高於人工心臟瓣膜患者 $(\mathrm{P}<0.001)$ 。歐洲和日本標準的TTR預測臨床和經濟結果的能力相 若。TTR理想的患者臨床併發症較少, 醫療費用更低。年輕患者以及 同時使用呋塞米、法莫替丁或辛伐他汀的患者其TTR較差。OAK測試 平均得分為 $54.1 \%$, 當中只有 24 名患者 $(13.8 \%)$ 取得總分 $\geq 75 \%$ 。

結論：無論適應症如何, 香港患者使用華法林的控制不佳。患者對使 用華法林的知識也不太理想。因此, 有必要加強患者對華法林的認 識。

INR therapeutic ranges as concurrent primary endpoints. Predictors for poor warfarin control were analysed as secondary endpoints. The impacts of TTR on both clinical and economic outcomes were investigated, using the European therapeutic range. Patient knowledge concerning warfarin therapy was also assessed, as were predictors of this knowledge.

\section{Methods}

\section{Patient recruitment}

The single-centre cohort study was conducted in the Prince of Wales Hospital, which is a regional acute public hospital in Hong Kong. Patients who received warfarin therapy in both the acute coronary syndrome registry and warfarin clinic for at least 1 year and who had their last visit from 1 January 2010 to 31 August 2015 were included. One year of warfarin therapy was presumed to be necessary for patients to develop stable INR. ${ }^{8}$ Patients aged $<41$ years and $>90$ years were excluded, due to the infrequency of warfarin therapy in both age-groups based on hospital records. Data for patient recruitment and subsequent patient review were retrieved through the Clinical Management System, which is a computerised patient medical record system.

\section{Time in therapeutic range summary}

Time in therapeutic range was defined as the fraction of INRs in range, with the percentage derived by 
dividing number of INRs within the therapeutic range by the total number of INRs recorded. ${ }^{17}$ Ideal TTR was defined as 70\%. ${ }^{6}$ Warfarin indications for individual patients were categorised in four groups: AF, PHV, both AF and PHV, and neither AF nor PHV (eg, deep vein thrombosis and pulmonary embolism). Associations of outcomes and adaptions of either guidelines were subsequently determined.

\section{Predictors of suboptimal time in therapeutic range}

Predictors of poor warfarin control, using the European therapeutic range, were regarded as secondary endpoints in our study. Patients were stratified into four quartiles according to TTR. Patients with TTR in Quartile 1 were considered to have poor warfarin control. Patients were compared across the four quartiles to identify predictors. Factors included were age, sex, co-morbidities, medication profile, and patient knowledge concerning warfarin therapy. Co-morbidities comprised hypertension, heart failure, thyroid disorder, liver dysfunction, and diabetes mellitus. Ten commonly prescribed medications were chosen for medication profile comparison, based on a pilot study of the first 20 recruited patients. The pilot study was conducted using the same recruitment criteria and the 20 patients were selected at random. All prescribed medications were recorded for these 20 patients. The 10 most commonly prescribed medications included aspirin, hydrochlorothiazide, metoprolol, diltiazem, diclofenac, famotidine, senna, simvastatin, lisinopril, and pantoprazole. For other cardiovascular medications, the potential impact was suspected with their high-frequency use in the cohort and further investigation was performed. The potential impact was detected using ongoing data collection based on low TTR and high thrombotic and bleeding events of patients with certain medications that were not included in the list of 10 medications previously. The investigators evaluated each additional medication carefully and its impact on the clinical outcomes.

\section{Impact of time in therapeutic range on clinical outcome}

Impacts of TTR on clinical outcomes were investigated; patient TTR values were stratified into four quartiles. Thrombotic events, bleeding complications, and overall incidences of complications were assessed. Stroke, pulmonary embolism, acute coronary syndrome, and arterial embolism were included as thrombotic events in our study. Severity of bleeding complications was classified based on discussion at the Control of Anticoagulation Subcommittee of the International Society of Thrombosis and Haemostasis. ${ }^{18}$ Major bleeding included: (1) fatal bleeding; and/or (2) symptomatic bleeding in a critical area or organ (eg, intracranial, intraspinal, intraocular, retroperitoneal, intraarticular or pericardial, or intramuscular with compartment syndrome); and/or (3) bleeding causing a decline in haemoglobin level of $\geq 2 \mathrm{~g} / \mathrm{dL}(1.24 \mathrm{mmol} / \mathrm{L})$, or leading to transfusion of $\geq 2$ units of whole blood or red cells. Otherwise, all non-major bleeds were regarded as minor bleeds.

\section{Impact of time in therapeutic range on economic outcome}

Impacts of TTR, using the European therapeutic range, on economic outcomes were investigated. Costs were calculated per day of warfarin therapy, such that patients' direct healthcare costs could be calculated regardless of the length of warfarin therapy. Direct healthcare costs related to warfarin (from the healthcare provider perspective) were calculated using the Hong Kong government gazette. ${ }^{19}$ Costs for INR examinations, procedures (eg, surgery and diagnostic tests, excluding INR examinations), hospitalisation, clinic visits, and overall costs were compared separately.

\section{Knowledge assessment}

Patient knowledge concerning warfarin therapy was assessed using the Oral Anticoagulation Knowledge (OAK) test. ${ }^{20}$ Question 14 of the original test was omitted from our study, because the frequencies of INR tests and follow-up visits were determined by local physicians in Hong Kong. A "Do not know" option was included to minimise random guessing. The assessment was translated into Chinese and performed via phone interviews from 2 January 2016 to 1 April 2016. Patient knowledge was considered satisfactory if a score of $\geq 75 \%$ was achieved. ${ }^{21}$ Predictors for OAK score performance were identified.

\section{Statistical analysis}

For descriptive statistics, frequencies and percentages were used for categorical variables; means \pm standard deviations were used for continuous variables. The Wilcoxon signed rank test, Chi squared test, Fisher's exact test, and one-way analysis of variance (pairwise comparison with the Tukey method) were used for comparisons of TTR with European and Japanese therapeutic ranges. Fisher's exact test and Mann-Whitney $U$ test were used to determine the impacts of TTR on clinical and economic outcomes, respectively. An ordinal regression model with stepwise selection was used to identify independent predictors for poor warfarin control. Multiple linear regression with stepwise selection for variables was used to determine predictors for OAK score. Two-sided $\mathrm{P}$ values $<0.05$ were considered 
statistically significant. All statistical analysis was performed by SPSS (Windows version 22.0; IBM Corp, Armonk [NY], US) and R (version 3.5.3; https://www.r-project.org/).

\section{Results}

\section{Baseline characteristics}

In total, 259 patients were included in the study; among them, 126 (48.6\%) were men. The mean patient age was $67.9 \pm 10.4$ years. The detailed demographic characteristics of the patients are shown in Table 1.

\section{Time in therapeutic range summary}

The overall mean INR was $2.3 \pm 0.3$. The median follow-up time for included patients was 2065 days (interquartile range $=1556-2065$ ). The median number of INR examinations was 46 (interquartile range $=33-73)$. Using the European therapeutic range, $34.5 \%$ of all measured INR values were within the therapeutic range. The overall TTR was
$40.2 \pm 17.1 \% ; 7.7 \%$ of patients had ideal TTR during the study period. Using the Japanese therapeutic range, $44.1 \%$ of all measured INR values were within the therapeutic range. The overall TTR was $49.1 \pm 16.1 \%$; this was significantly higher than the TTR when using the European therapeutic range $(\mathrm{P}<0.001)$. Notably, $12.4 \%$ of all patients had ideal TTR during the study period.

Mean TTR values for different indications were compared, as shown in Table 2. When using the European therapeutic range, the mean TTR with an indication for AF was significantly higher than both the mean TTR with an indication for PHV $(\mathrm{P}<0.001)$ and the mean TTR with an indication for AF and PHV $(\mathrm{P}<0.001)$. When using the Japanese therapeutic range, the mean TTR with an indication for AF was also significantly higher than the mean TTR with an indication for both AF and PHV $(\mathrm{P}<0.001)$. The mean TTR values were significantly higher when using the Japanese therapeutic range than when using the European therapeutic range within each indication category.

TABLE I. Demographics and indications for warfarin using European and Japanese therapeutic ranges*

\begin{tabular}{|c|c|c|c|c|c|c|c|}
\hline & \multirow[t]{2}{*}{ Overall $(n=259)$} & \multicolumn{3}{|c|}{ European therapeutic range } & \multicolumn{3}{|c|}{ Japanese therapeutic range } \\
\hline & & $\begin{array}{l}\text { Ideal TTR } \\
(n=20)\end{array}$ & $\begin{array}{l}\text { Non-ideal TTR } \\
(n=239)\end{array}$ & $P$ value & $\begin{array}{l}\text { Ideal TTR } \\
(n=32)\end{array}$ & $\begin{array}{l}\text { Non-ideal TTR } \\
(n=227)\end{array}$ & $P$ value \\
\hline \multicolumn{8}{|l|}{ Demographics } \\
\hline Age (years) & $67.9 \pm 10.4$ & $67.8 \pm 9.9$ & $67.9 \pm 10.4$ & 0.973 & $68.8 \pm 11.3$ & $67.8 \pm 10.2$ & 0.612 \\
\hline Male sex & $126(48.6 \%)$ & $11(55.0 \%)$ & $115(48.1 \%)$ & 0.554 & 19 (59.4\%) & 107 (47.1\%) & 0.195 \\
\hline Indication for warfarin & & & & 0.009 & & & 0.184 \\
\hline $\mathrm{AF}$ & $127(49.0 \%)$ & $17(85.0 \%)$ & $110(46.0 \%)$ & & $21(65.6 \%)$ & $106(46.7 \%)$ & \\
\hline PHV & $52(20.1 \%)$ & $1(5.0 \%)$ & $51(21.3 \%)$ & & $6(18.8 \%)$ & $46(20.3 \%)$ & \\
\hline Both AF and PHV & $63(24.3 \%)$ & $1(5.0 \%)$ & $62(25.9 \%)$ & & $4(12.5 \%)$ & $59(26.0 \%)$ & \\
\hline Neither AF nor PHV & $17(6.6 \%)$ & $1(5.0 \%)$ & $16(6.7 \%)$ & & $1(3.1 \%)$ & $16(7.0 \%)$ & \\
\hline
\end{tabular}

Abbreviations: $\mathrm{AF}=$ atrial fibrillation; $\mathrm{PHV}=$ prosthetic heart valve; TTR = time in therapeutic range

* Data are shown as mean \pm standard deviation or No. (\%), unless otherwise specified

TABLE 2. TTR with different indications for warfarin using European and Japanese therapeutic ranges

\begin{tabular}{|c|c|c|c|c|c|c|c|}
\hline & \multicolumn{3}{|c|}{ European therapeutic range } & \multicolumn{3}{|c|}{ Japanese therapeutic range } & \multirow[t]{2}{*}{$\mathbf{P}$ value } \\
\hline & Mean TTR & SD & P value* & Mean TTR & SD & P value* & \\
\hline Indication for warfarin & & & $<0.001$ & & & $<0.001$ & \\
\hline $\mathrm{AF}$ & $48.0 \%$ & $16.3 \%$ & & $53.4 \%$ & $16.3 \%$ & & $<0.001$ \\
\hline PHV & $30.5 \%$ & $13.9 \%$ & & $48.0 \%$ & $14.5 \%$ & & $<0.001$ \\
\hline Both AF and PHV & $32.0 \%$ & $13.6 \%$ & & $42.9 \%$ & $15.2 \%$ & & $<0.001$ \\
\hline Neither AF nor PHV & $41.9 \%$ & $14.7 \%$ & & $43.0 \%$ & $14.3 \%$ & & $<0.001$ \\
\hline
\end{tabular}

Abbreviations: $\mathrm{AF}=$ atrial fibrillation; $\mathrm{PHV}=$ prosthetic heart valve; $\mathrm{SD}=$ standard deviation; TTR = time in therapeutic range

* One-way analysis of variance, comparing mean TTR values within each therapeutic range

† Paired $t$ test, comparing mean TTR using European and Japanese therapeutic ranges 


\section{Predictors of suboptimal time in therapeutic range}

Patients were divided into four quartiles according to their TTR, using the European therapeutic range (Table 3). Predictors were determined by performing regression across the four quartiles. Adjusted odds ratios (ORs) for poor TTR were calculated. The results showed that younger age was associated with worse TTR, as were concurrent use of furosemide, famotidine, or simvastatin.

\section{Impact of time in therapeutic range on clinical outcome}

Clinical outcomes were compared between the two therapeutic ranges (Table 4). Of the 259 patients, $35.9 \%$ experienced complications. Of the 39 patients with thrombotic events, $41.0 \%$ had recurrent non-ST-elevation myocardial infarction and 33.3\% had stroke. Among patients with bleeding complications, $68.8 \%$ experienced minor bleeding. Patients with ideal TTR had significantly fewer overall complications and bleeding complications, compared with patients with non-ideal TTR, in both European and Japanese therapeutic ranges. All patients who had complications were those with non-ideal TTR, using the European therapeutic range. When patients were further stratified into quartiles based on TTR using the European therapeutic range, TTR exhibited statistically significant associations with each tested clinical outcome (Table 5).

\section{Impact of time in therapeutic range on economic outcome}

Healthcare costs are expressed in terms of US\$ per year (US\$1=HK\$7.8), as shown in Table 4. When including all services related to warfarin, average patient costs were US $\$ 809.9 /$ year. In terms of economic outcomes, the INR examination, clinical visit, and total healthcare costs were significantly lower for patients with ideal TTR when using either European or Japanese therapeutic ranges. Using the Japanese therapeutic range, patients with ideal TTR also had lower hospitalisation costs. When using the European therapeutic range, healthcare provider costs increased by US $\$ 530.1$ year for each patient with non-ideal TTR.

\section{Knowledge assessment}

In total, 174 patients completed the OAK test, with

TABLE 3. Predictors of poor TTR using European therapeutic range*

\begin{tabular}{|c|c|c|c|c|c|c|}
\hline & Quartile $1(n=65)$ & Quartile $2(n=65)$ & Quartile $3(n=65)$ & Quartile 4 (n=64) & $\begin{array}{l}\text { aOR for poor TTR } \\
(95 \% \mathrm{Cl})\end{array}$ & $P$ value \\
\hline TTR, range & $0 \%-27.8 \%$ & $27.9 \%-38.5 \%$ & $38.5 \%-50 \%$ & $50.0 \%-93.3 \%$ & & \\
\hline \multicolumn{7}{|l|}{ Demographics } \\
\hline Age & $64.9 \pm 10.0$ & $67.2 \pm 10.8$ & $70.4 \pm 10.3$ & $69.0 \pm 9.7$ & $0.94(0.92-0.97)$ & $<0.001$ \\
\hline Male sex & $35(53.8 \%)$ & $26(40.0 \%)$ & $28(43.1 \%)$ & $37(57.8 \%)$ & - & \\
\hline \multicolumn{7}{|l|}{ Medical history } \\
\hline Hypertension & $23(35.4 \%)$ & $28(43.1 \%)$ & $29(44.6 \%)$ & $27(42.2 \%)$ & - & \\
\hline Heart failure & $28(43.1 \%)$ & $31(47.7 \%)$ & $24(36.9 \%)$ & $23(35.9 \%)$ & - & \\
\hline Thyroid disorder & $8(12.3 \%)$ & $7(10.8 \%)$ & $4(6.2 \%)$ & $8(12.5 \%)$ & - & \\
\hline Liver dysfunction & $11(16.9 \%)$ & $11(16.9 \%)$ & $3(4.6 \%)$ & $9(14.1 \%)$ & - & \\
\hline Diabetes mellitus & $17(26.2 \%)$ & $22(33.8 \%)$ & $24(36.9 \%)$ & $15(23.4 \%)$ & - & \\
\hline \multicolumn{7}{|l|}{ Medication } \\
\hline Aspirin & $22(33.8 \%)$ & $26(40.0 \%)$ & $32(49.2 \%)$ & $9(14.1 \%)$ & $1.72(0.98-3.03)$ & 0.059 \\
\hline Furosemide & $47(72.3 \%)$ & $41(63.1 \%)$ & $32(49.2 \%)$ & 26 (40.6\%) & $2.61(1.63-4.21)$ & $<0.001$ \\
\hline Carvedilol & $9(13.8 \%)$ & $12(18.5 \%)$ & $15(23.1 \%)$ & $4(6.3 \%)$ & - & \\
\hline Diltiazem & $8(12.3 \%)$ & $8(12.3 \%)$ & $6(9.2 \%)$ & $12(18.8 \%)$ & - & \\
\hline Diclofenac & $4(6.2 \%)$ & $6(9.2 \%)$ & $6(9.2 \%)$ & $6(9.4 \%)$ & $0.54(0.24-1.22)$ & 0.139 \\
\hline Famotidine & $39(60.0 \%)$ & $43(66.2 \%)$ & $39(60.0 \%)$ & $27(42.2 \%)$ & $1.68(1.04-2.73)$ & 0.035 \\
\hline Senna & 29 (44.6\%) & 25 (38.5\%) & 24 (36.9\%) & $17(26.6 \%)$ & - & \\
\hline Pantoprazole & 25 (38.5\%) & 22 (33.8\%) & $20(30.8 \%)$ & $11(17.2 \%)$ & $1.63(0.99-2.71)$ & 0.057 \\
\hline Lisinopril & $28(43.1 \%)$ & 27 (41.5\%) & 27 (41.5\%) & $19(29.7 \%)$ & - & \\
\hline Simvastatin & $34(52.3 \%)$ & 29 (44.6\%) & $32(49.2 \%)$ & 19 (29.7\%) & $1.67(1.00-2.78)$ & 0.048 \\
\hline
\end{tabular}

Abbreviations: $95 \% \mathrm{Cl}=95 \%$ confidence interval; $\mathrm{aOR}=$ adjusted odds ratio; $\mathrm{TTR}=$ time in therapeutic range

* Data are shown as mean \pm standard deviation or No. (\%), unless otherwise specified 
TABLE 4. Clinical and economic outcomes using European and Japanese therapeutic ranges*

\begin{tabular}{|c|c|c|c|c|c|c|c|c|c|}
\hline & \multirow{2}{*}{$\begin{array}{l}\text { Overall } \\
(n=259)\end{array}$} & \multicolumn{4}{|c|}{ European therapeutic range } & \multicolumn{4}{|c|}{ Japanese therapeutic range } \\
\hline & & $\begin{array}{l}\text { Ideal TTR } \\
(n=20)\end{array}$ & $\begin{array}{l}\text { Non-ideal } \\
\text { TTR }(n=239)\end{array}$ & OR (95\% Cl) & $\begin{array}{c}P \\
\text { value }\end{array}$ & $\begin{array}{l}\text { Ideal TTR } \\
(n=32)\end{array}$ & $\begin{array}{l}\text { Non-ideal } \\
\text { TTR }(n=227)\end{array}$ & OR (95\% Cl) & $\begin{array}{c}P \\
\text { value }\end{array}$ \\
\hline \multicolumn{10}{|l|}{ Clinical outcomes } \\
\hline Complications & 93 (35.9\%) & 0 & $93(38.9 \%)$ & - & 0.001 & $4(12.5 \%)$ & $89(39.2 \%)$ & $0.22(0.08-0.65)$ & 0.006 \\
\hline Thrombotic events & 39 (15.1\%) & 0 & 39 (16.3\%) & - & $0.051 \dagger$ & $1(3.1 \%)$ & $38(16.7 \%)$ & $0.16(0.02-1.21)$ & 0.076 \\
\hline $\begin{array}{l}\text { Bleeding } \\
\text { complications }\end{array}$ & $64(24.7 \%)$ & 0 & $64(26.8 \%)$ & - & $0.005 \dagger$ & $3(9.4 \%)$ & $61(26.9 \%)$ & $0.28(0.08-0.96)$ & 0.042 \\
\hline \multicolumn{10}{|l|}{$\begin{array}{l}\text { Economic outcomes } \\
\text { (US\$) }\end{array}$} \\
\hline $\begin{array}{l}\text { INR examination } \\
\text { costs }\end{array}$ & $605.8 \pm 450.8$ & $260.5 \pm 87.4$ & $634.8 \pm 458.0$ & $0.56(0.43-0.74)$ & $<0.001$ & $303.7 \pm 100.4$ & $648.5 \pm 465.7$ & 0.70 & $<0.001$ \\
\hline Procedure costs & $105.8 \pm 332.3$ & $2.7 \pm 12.1$ & $114.4 \pm 344.6$ & $0.40(0.07-2.23)$ & 0.296 & $7.7 \pm 23.0$ & $119.7 \pm 352.9$ & $0.71(0.44-1.13)$ & 0.148 \\
\hline $\begin{array}{l}\text { Hospitalisation } \\
\text { costs }\end{array}$ & $23.1 \pm 52.0$ & $0.3 \pm 1.2$ & $25.1 \pm 53.7$ & $<0.01(<0.01-2.16)$ & 0.061 & $3.0 \pm 7.6$ & $26.0 \pm 54.9$ & $0.05(0.002-0.55)$ & 0.015 \\
\hline Clinical visit costs & $38.7 \pm 22.5$ & $30.4 \pm 12.3$ & $39.4 \pm 23.0$ & $0.03(0.001-0.47)$ & 0.013 & $30.6 \pm 11.1$ & $39.9 \pm 23.4$ & $0.03(0.002-0.26)$ & 0.002 \\
\hline $\begin{array}{l}\text { Total healthcare } \\
\text { costs }\end{array}$ & $809.9 \pm 630.5$ & $320.9 \pm 101.6$ & $851.0 \pm 639.1$ & $0.61(0.47-0.78)$ & $<0.001$ & $373.8 \pm 122.2$ & $871.7 \pm 649.0$ & $0.75(0.66-0.86)$ & $<0.001$ \\
\hline
\end{tabular}

Abbreviations: $95 \% \mathrm{Cl}=95 \%$ confidence interval; INR = international normalised ratio; OR = odds ratio; TTR = time in therapeutic range

* Data are shown as mean \pm standard deviation or No. (\%), unless otherwise specified. Unless specified, P value was calculated for OR

† Fisher's exact test, comparing counts across ideal TTR and non-ideal TTR groups

TABLE 5. Clinical outcomes of four quartiles using European therapeutic range*

\begin{tabular}{cccccc}
\hline & Quartile 1 (n=65) & Quartile 2 (n=65) & Quartile 3 (n=65) & Quartile 4 (n=64) & P value \\
\hline Clinical outcomes & & & & & \\
Complications & $32(49.2 \%)$ & $30(46.2 \%)$ & $21(32.3 \%)$ & $10(15.6 \%)$ & $<0.001$ \\
Thrombotic events & $11(16.9 \%)$ & $14(21.5 \%)$ & $12(18.5 \%)$ & $2(3.1 \%)$ & 0.027 \\
Bleeding complications & $25(38.5 \%)$ & $20(30.8 \%)$ & $11(16.9 \%)$ & $8(12.5 \%)$ & $<0.001$ \\
\hline
\end{tabular}

* Data are shown as No (\%), unless otherwise specified. Patients with TTR in Quartile I were considered to have poor warfarin control. Mantel-Haenszel Chi squared test for trends was used to test the significance of the outcome effect across four quartiles

a mean score of $54.1 \%$ correct for the 19 questions used in our version of the test. The mean duration of warfarin therapy for this subgroup of patients during the study period was $4.8 \pm 1.4$ years. Only 24 (13.8\%) patients achieved the satisfactory overall test score of $\geq 75 \%$. Of the 19 questions in the test, only four were answered correctly by $\geq 70 \%$ of respondents (Table 6).

Multiple linear regression revealed that respondents with older age (adjusted $\beta=-0.17$; 95\% confidence interval $[\mathrm{CI}]=-0.23$ to -0.11 ; $\mathrm{P}=0.001$ ) or co-morbid diabetes (adjusted $\beta=-1.21$; $95 \% \mathrm{CI}=-2.29$ to $-0.12 ; \mathrm{P}=0.03$ ) were more likely to have low scores on the OAK test. In contrast, respondents with co-morbid hypertension (adjusted $\beta=1.68 ; 95 \% \mathrm{CI}=0.56-2.80 ; \mathrm{P}=0.004$ ) or co-morbid thyroid dysfunction (adjusted $\beta=2.38$; 95\% $\mathrm{CI}=0.80-3.97 ; \mathrm{P}=0.003$ ) were more likely to have high scores on the OAK test. Respondents with better TTR tended to be more likely to have high scores on the OAK test, although this difference was not statistically significant (adjusted $\beta=2.73$; $95 \% \mathrm{CI}=-0.21-5.68 ; \mathrm{P}=0.069$ ).

\section{Discussion}

\section{Status of warfarin control in Hong Kong}

The mean TTR observed in our study was lower than that observed in studies performed in Western nations. A meta-analysis of 40 studies using the European therapeutic range identified a mean TTR of $75.2 \%$ after 4 to 12 months of warfarin management. ${ }^{22}$ A study focusing on warfarin use in Japanese patients using the Japanese therapeutic range showed an overall TTR of $69.7 \%$ in patients with non-valvular AF. ${ }^{23}$ Studies in Hong Kong showed that the mean TTR for target INR of 2.0 to 3.0 in patients with AF improved from $24.2 \%$ 
TABLE 6. Results of oral anticoagulation knowledge test

\begin{tabular}{|c|c|c|}
\hline & $\begin{array}{l}\text { Answered } \\
\text { correctly }\end{array}$ & Do not know \\
\hline Q1. Consequence of a PT/INR value above target range & $28.2 \%$ & $16.7 \%$ \\
\hline Q2. Ability to distinguish among different strengths of warfarin & $81.6 \%$ & $17.2 \%$ \\
\hline Q3. Condition to seek medical attention & $69.0 \%$ & $28.7 \%$ \\
\hline Q4. Eating a large amount of leafy green vegetables while taking warfarin & $50.6 \%$ & $30.0 \%$ \\
\hline Q5. Type of vitamin which interacts with warfarin & $44.8 \%$ & $51.7 \%$ \\
\hline Q6. Significance of drug-drug interactions with warfarin & $35.6 \%$ & $21.3 \%$ \\
\hline Q7. Knowledge concerning PT/INR test & $83.3 \%$ & $8.6 \%$ \\
\hline Q8. Indications for warfarin & $82.8 \%$ & $10.9 \%$ \\
\hline Q9. Consequences of a PT/INR value below therapeutic range & $52.3 \%$ & $23.6 \%$ \\
\hline Q10. Knowledge concerning drug-drug interactions of warfarin with aspirin or NSAIDs & $21.8 \%$ & $54.6 \%$ \\
\hline Q11. Condition to seek medical attention & $50.6 \%$ & $17.8 \%$ \\
\hline Q12. Consequences of skipping dose & $25.3 \%$ & $44.8 \%$ \\
\hline Q13. Effects of alcohol during taking warfarin & $55.8 \%$ & $36.2 \%$ \\
\hline Q15. Knowledge concerning monitoring for bleeding signs & $70.7 \%$ & $13.8 \%$ \\
\hline Q16. Management for missing dose & $48.9 \%$ & $28.2 \%$ \\
\hline Q17. Knowledge concerning food-drug interactions & $68.4 \%$ & $4.6 \%$ \\
\hline Q18. Precautions before PT/INR check & $55.8 \%$ & $35.6 \%$ \\
\hline Q19. Knowledge concerning interactions of over-the-counter products with warfarin & $55.2 \%$ & $28.2 \%$ \\
\hline Q20. Consequence of a PT/INR value above target range & $47.1 \%$ & $24.1 \%$ \\
\hline
\end{tabular}

Abbreviations: NSAIDs = nonsteroidal anti-inflammatory drugs; PT/INR = prothrombin time and international normalised ratio

to $39.7 \%$ in the past decade. ${ }^{24,25}$ Our study showed better warfarin control in patients with AF (mean TTR $=48.0 \%$ ), compared with past local data; however, the rate of control remains unsatisfactory. A prior retrospective study demonstrated a mean TTR of $72.5 \%$ in Swedish patients with mechanical heart valve prosthesis; another study showed that the mean TTR was $47.48 \%$ in Malaysian patients with mechanical heart valve(s) replacement. ${ }^{26,27}$ The mean TTR in patients with PHV in this study was $30.5 \%$, which was lower than the previously reported rate. Our study also demonstrated that warfarin control was worse in patients with PHV than in patients with AF.

The lower TTR in Hong Kong, compared with that in Western nations, could be attributed to ethnicity. Geographical differences in the genetic polymorphism profile between Hong Kong and Western nations could lead to differences in warfarin metabolism and warfarin dosing. ${ }^{28}$ Moreover, previous evidence suggests that individuals of East Asian ethnicity are more likely to experience intracranial haemorrhage, compared with individuals of Caucasian ethnicity (in that study, "white race/ethnicity") who exhibit comparable levels of warfarin control. ${ }^{29}$ Notably, the possibility that physicians targeted a lower INR range in Hong Kong could not be ruled out in this study.

\section{European versus Japanese therapeutic range}

The overall predictive abilities of European and Japanese therapeutic ranges were similar. The calculated ORs for each economic outcome across European and Japanese therapeutic ranges were similar, with the exception of procedural and hospitalisation costs. For clinical outcomes, ORs could not be calculated to compare ideal TTR with non-ideal TTR, given that there were no complications in the ideal TTR group. However, there were complications in the group with ideal TTR based on the Japanese therapeutic range. The ORs calculated showed that the Japanese therapeutic range could be used to predict clinical outcomes. Notably, a lower INR target can be established in Hong Kong. However, a larger, well-designed randomised controlled trial is needed to establish non-inferiority in terms of clinical outcomes, as well as superiority in terms of economic outcomes, when using the Japanese therapeutic range.

\section{Impacts of time in therapeutic range on outcomes}

The level of warfarin control has been associated with clinical outcomes. A systematic review of 47 studies revealed that TTR was negatively correlated with major bleeding and thromboembolic events. ${ }^{30}$ 
Our results were consistent in demonstrating an association of TTR with clinical outcome, which indicated that patients with worse TTR were more likely to experience overall complications, thrombotic events, and bleeding complications. Moreover, TTR has been associated with economic outcomes. A previous study in the US showed that patients with AF whose TTR was $<60 \%$ had higher total healthcare and stroke-related costs. ${ }^{31}$ Our study demonstrated similar results, using a TTR cut-off of $70 \%$. With better warfarin control, corresponding healthcare expenses can be reduced; many such expenses are borne by the government.

\section{Predictors for suboptimal time in therapeutic range}

Predictors for suboptimal TTR have been investigated in previous studies. Notably, heart failure has been highly associated with poor warfarin control $^{8,23}$; however, this association was not supported by our findings. In contrast, our study showed that younger patients were more likely to have poor TTR. This association might be related to improved medication adherence in older patients, because of better health consciousness among those individuals. ${ }^{32,33}$ Concurrent use of furosemide, famotidine, or simvastatin (in combination with warfarin) was associated with poor TTR. Despite common concurrent use of simvastatin and warfarin, the anticoagulant effect of warfarin is reportedly $8 \%$ to $15 \%$ stronger in simvastatin-treated patients, due to the CYP 2C9*3 polymorphism. ${ }^{34}$ Regarding concurrent use of warfarin and pantoprazole, altered warfarin absorption and metabolism have been observed during in vitro studies of proton pump inhibitor treatment ${ }^{35}$; however, there is a lack of supporting clinical evidence. ${ }^{36}$ Our study showed a tendency for enhanced likelihood of poor TTR control in patients with concurrent use of pantoprazole, although this association was not statistically significant. Thus, the influence of proton pump inhibitor use on warfarin control remains unclear. Patients with concurrent use of aspirin and warfarin exhibited a tendency for enhanced risk of poor TTR; this association was also not statistically significant. We noted a considerable reduction in the number of patients in the fourth TTR quartile (14.1\%), compared with the other three groups (range, 33.8-49.2\%). Concurrent use of aspirin and warfarin is known to enhance the risk of major bleeding, which could cause physicians to approach anticoagulation control more conservatively. ${ }^{37}$ Furthermore, the use of aspirin and poor TTR have both been independently associated with higher bleeding risk, while poor TTR has been regarded as an independent contributor to all-cause mortality. ${ }^{38}$ Therefore, regardless of the concurrent use of aspirin, optimal TTR should be achieved with regard to the appropriate INR therapeutic range to reduce complications in patients receiving warfarin therapy.

\section{Patient knowledge concerning warfarin therapy}

According to validation studies performed by Zeolla et $\mathrm{al}^{20}{ }^{20}$ the mean OAK score among long-term warfarin users was $72 \%$. A study in Malaysia revealed that only $11.2 \%$ of patients achieved a satisfactory score, with a mean OAK score of $48 \%$ for the cohort. ${ }^{39}$ Similar results were achieved in our study; the mean score was $54.1 \%$ and $13.8 \%$ of patients achieved a score of $\geq 75 \%$. Poor OAK score could be attributed to restricted medical consultation time, leading to a lack of knowledge concerning respective diseases and medications ${ }^{40}$ Patients with older age were more likely to have low OAK scores, which was consistent with the findings of a previous study that demonstrated a negative correlation between age and warfarin knowledge. ${ }^{41}$ Nonetheless, the observed relationships of co-morbidities with warfarin knowledge require further analyses to establish underlying explanations.

\section{Study limitations}

This study had several important limitations. This was a single-centre study with limited sample size and study population distribution skewed towards AF patients concerning warfarin indications. The target INR range for included patients was unknown. Notably, some physicians may have set a lower goal of 1.5 to 2.5 in patients with higher risk of bleeding. Patient TTR could have been affected by medication delay or refusal due to medical procedures. The impacts of TTR on medication costs were not investigated because differences in available strengths of warfarin led to various combinations of warfarin prescriptions. Moreover, we could not adjust for diet, use of traditional Chinese medicine or complementary alternative medications, and medication non-compliance as factors that may influence warfarin control. The OAK test was amended to fit our local practices and was not administered to some of the recruited patients in this study. Further validation is needed concerning the Chinese version of the amended OAK test.

\section{Conclusion}

Warfarin use in Hong Kong patients was poorly controlled, regardless of indication. Patients with indications for AF had better warfarin control. Using the Japanese therapeutic range, the level of warfarin control remained unsatisfactory. Our study showed that TTR could be a predictor for both economic and clinical outcomes. Younger age was found to be an independent predictor of poor warfarin control, as were concurrent use of aspirin or simvastatin. 
Patients had poor knowledge concerning INR value and interpretation. More education is needed regarding drug-drug interactions of warfarin and consequences of missed doses.

\section{Author contributions}

Concept or design: VWY Lee, BPY Yan.

Acquisition of data: IMH Lee, SKS Mak.

Analysis or interpretation of data: ASM Lam, VWY Lee, BPY Yan.

Drafting of the manuscript: ASM Lam, VWY Lee, BPY Yan.

Critical revision for important intellectual content: All authors.

All authors had full access to the data, contributed to the study, approved the final version for publication, and take responsibility for its accuracy and integrity.

\section{Conflicts of interest}

As an editor of the journal, BPY Yan was not involved in the peer review process. Other authors have disclosed no conflicts of interest.

\section{Declaration}

This manuscript was posted on Research Square as a registered online preprint (https://doi.org/10.21203/rs.2.15276/v1).

\section{Funding/support}

This research received no specific grant from any funding agency in the public, commercial, or not-for-profit sectors.

\section{Ethics approval}

The study was approved by the Joint Chinese University of Hong Kong-New Territories East Cluster Clinical Research Ethics Committee (Ref CRE 2013.667). Informed verbal consent was obtained from patients participating in knowledge assessment, which was conducted via phone interview. The need for patient consent was waived by the Ethics Committee for the retrospective cohort study because no personal identifiers or related information were obtained during the data collection process.

\section{References}

1. Jabre P, Roger VL, Murad MH, et al. Mortality associated with atrial fibrillation in patients with myocardial infarction a systematic review and meta-analysis. Circulation 2011;123:1587-93.

2. Wolf PA, Abbott RD, Kannel WB. Atrial fibrillation as an independent risk factor for stroke: the Framingham Study. Stroke 1991;22:983-8.

3. Cáceres-Lóriga FM, Pérez-López H, Santos-Gracia J, Morlans-Hernandez K. Prosthetic heart valve thrombosis: pathogenesis, diagnosis and management. Int J Cardiol 2006;110:1-6

4. Aguilar MI, Hart R. Oral anticoagulants for preventing stroke in patients with non-valvular atrial fibrillation and no previous history of stroke or transient ischemic attacks. Cochrane Database Syst Rev 2005;(3):CD001927.

5. Cannegieter SC, Rosendaal FR, Briët E. Thromboembolic and bleeding complications in patients with mechanical heart valve prostheses. Circulation 1994;89:635-41.
6. Kirchhof P, Benussi S, Kotecha D, et al. 2016 ESC Guidelines for the management of atrial fibrillation developed in collaboration with EACTS. Eur Heart J 2016;37:2893-962.

7. Asarcıklı LD, Şen T, İpek EG, et al. Time in Therapeutic Range (TTR) value of patients who use warfarin and factors which influence TTR. J Am Coll Cardiol 2013;62:C127-8.

8. Nelson WW, Choi JC, Vanderpoel J, et al. Impact of co-morbidities and patient characteristics on international normalized ratio control over time in patients with nonvalvular atrial fibrillation. Am J Cardiol 2013;112:50912.

9. Cancino RS, Hylek EM, Reisman JI, Rose AJ. Comparing patient-level and site-level anticoagulation control as predictors of adverse events. Thromb Res 2014;133:652-6.

10. JCS Joint Working Group. Guidelines for Pharmacotherapy of Atrial Fibrillation (JCS 2013). Circ J 2014;78:1997-2021.

11. Yasaka M, Minematsu K, Yamaguchi T. Optimal intensity of international normalized ratio in warfarin therapy for secondary prevention of stroke in patients with nonvalvular atrial fibrillation. Intern Med 2001;40:1183-8.

12. Holbrook AM, Pereira JA, Labiris R, et al. Systematic overview of warfarin and its drug and food interactions. Arch Intern Med 2005;165:1095-106.

13. Leite PM, Martins MAP, Castilho RO. Review on mechanisms and interactions in concomitant use of herbs and warfarin therapy. Biomed Pharmacother 2016;83:1421.

14. Wofford JL, Wells MD, Singh S. Best strategies for patient education about anticoagulation with warfarin: a systematic review. BMC Health Serv Res 2008;8:40.

15. Kagansky N, Knobler H, Rimon E, Ozer Z, Levy S. Safety of anticoagulation therapy in well-informed older patients. Arch Intern Med 2004;164:2044-50.

16. Zhou Z, Hu D. An epidemiological study on the prevalence of atrial fibrillation in the Chinese population of mainland China. J Epidemiol 2008;18:209-16.

17. Schmitt L, Speckman J, Ansell J. Quality assessment of anticoagulation dose management: comparative evaluation of measures of time-in-therapeutic range. J Thromb Thrombolysis 2003;15:213-6.

18. Schulman S, Kearon C, Subcommittee on Control of Anticoagulation of the Scientific and Standardization Committee of the International Society on Thrombosis and Haemostasis. Definition of major bleeding in clinical investigations of antihemostatic medicinal products in non-surgical patients. J Thromb Haemost 2005;3:692-4.

19. Government Logistics Department, Hong Kong SAR Government. Hospital Authority Ordinance (Chapter 113). Revision to list of public charges. Available from: http://www.gld.gov.hk/egazette/pdf/20172124/ egn201721243884.pdf. Accessed 6 Dec 2017.

20. Zeolla MM, Brodeur MR, Dominelli A, Haines ST, Allie ND. Development and validation of an instrument to determine patient knowledge: the Oral Anticoagulation Knowledge Test. Ann Pharmacother 2006;40:633-8.

21. Rahmani P, Guzman CL, Blostein MD, Tabah A, Muladzanov A, Kahn SR. Patients' knowledge of anticoagulation and its association with clinical characteristics, INR Control and warfarin-related adverse events. Blood 2013;122:1738.

22. Erkens PM, ten Cate H, Büller HR, Prins MH. Benchmark for time in therapeutic range in venous thromboembolism: a systematic review and meta-analysis. PLoS One 
2012;7:e42269.

23. Tomita H, Kadokami T, Momii H, et al. Patient factors against stable control of warfarin therapy for Japanese non-valvular atrial fibrillation patients. Thromb Res 2013;132:537-42.

24. Leung CS, Tam KM. Antithrombotic treatment of atrial fibrillation in a regional hospital in Hong Kong. Hong Kong Med J 2003;99:179-85.

25. Li WH, Huang D, Chiang CE, et al. Efficacy and safety of dabigatran, rivaroxaban, and warfarin for stroke prevention in Chinese patients with atrial fibrillation: the Hong Kong Atrial Fibrillation Project. Clin Cardiol 2017;40:222-9.

26. Grzymala-Lubanski B, Svensson PJ, Renlund H, Jeppsson A, Själander A. Warfarin treatment quality and prognosis in patients with mechanical heart valve prosthesis. Heart 2017;103:198-203.

27. Tan CS, Fong AY, Jong YH, Ong TK. INR control of patients with mechanical heart valve on long-term warfarin therapy. Glob Heart 2018;13:241-4.

28. Gaikwad T, Ghosh K, Shetty S. VKORC1 and CYP2C9 genotype distribution in Asian countries. Thromb Res 2014;134:537-44.

29. Shen AY, Yao JF, Brar SS, Jorgensen MB, Chen W. Racial/ ethnic differences in the risk of intracranial hemorrhage among patients with atrial fibrillation. J Am Coll Cardiol 2007;50:309-15.

30. Wan Y, Heneghan C, Perera R, et al. Anticoagulation control and prediction of adverse events in patients with atrial fibrillation: a systematic review. Circ Cardiovasc Qual Outcomes 2008;1:84-91.

31. Deitelzweig S, Evans M, Hillson E, et al. Warfarin time in therapeutic range and its impact on healthcare resource utilization and costs among patients with nonvalvular atrial fibrillation. Curr Med Res Opin 2016;32:87-94.

32. Skeppholm M, Friberg L. Adherence to warfarin treatment among patients with atrial fibrillation. Clin Res Cardiol 2014;103:998-1005.
33. Kang CD, Tsang PP, Li WT, et al. Determinants of medication adherence and blood pressure control among hypertensive patients in Hong Kong: a cross-sectional study. Int J Cardiol 2015;182:250-7.

34. Andersson ML, Mannheimer B, Lindh JD. The effect of simvastatin on warfarin anticoagulation: a Swedish register-based nationwide cohort study. Eur J Clin Pharmacol 2019;75:1387-92.

35. Li XQ, Andersson TB, Ahlström M, Weidolf L. Comparison of inhibitory effects of the proton pump-inhibiting drugs omeprazole, esomeprazole, lansoprazole, pantoprazole, and rabeprazole on human cytochrome P450 activities. Drug Metab Dispos 2004;32:821-7.

36. Henriksen DP, Stage TB, Hansen MR, Rasmussen L, Damkier P, Pottegård A. The potential drug-drug interaction between proton pump inhibitors and warfarin. Pharmacoepidemiol Drug Saf 2015;24:1337-40.

37. Dans AL, Connolly SJ, Wallentin L, et al. Concomitant use of antiplatelet therapy with dabigatran or warfarin in the Randomized Evaluation of Long-Term Anticoagulation Therapy (RE-LY) trial. Circulation 2013;127:634-40.

38. Proietti M, Lip GY. Impact of quality of anticoagulation control on outcomes in patients with atrial fibrillation taking aspirin: an analysis from the SPORTIF trials. Int J Cardiol 2018;252:96-100.

39. Matalqah LM, Radaideh K, Sulaiman SA, Hassali MA, Kader MA. An instrument to measure anticoagulation knowledge among Malaysian community: a translation and validation study of the Oral Anticoagulation Knowledge (OAK) Test. Asian J Biomed Pharm Sci 2013;3:30-7.

40. Lee VW, Tam CS, Yan BP, Yu CM, Lam YY. Barriers to warfarin use for stroke prevention in patients with atrial fibrillation in Hong Kong. Clin Cardiol 2013;36:166-71.

41. Hasan SS, Shamala R, Syed IA, et al. Factors affecting warfarin-related knowledge and INR control of patients attending physician- and pharmacist-managed anticoagulation clinics. J Pharm Pract 2011;24:485-93. 